\title{
Hiperfosfatemia na insuficiência renal aguda: Relato de caso
}

\author{
Marlos Melo Duarte ${ }^{1}$, Francisco Lima Silva ${ }^{2}$, Paulo Victor Garrêto Rodrigues dos \\ Santos ${ }^{1}$. \\ ${ }^{I}$ Médico Veterinário Residente do Hospital Veterinário da Universidade Federal do Piauí-Teresina/PI \\ ${ }^{2}$ Professor Doutor do Departamento de Clinica e Cirurgia Veterinária da UFPI - Teresina/PI \\ *Autor para correspondência,_E-mail: marlosloarte_@hotmail.com
}

\begin{abstract}
RESUMO. Este relato de caso mostra a preocupação com os altos índices de hiperfosfatemia na insuficiência renal aguda em cães, não deixando de lado os outros sinais que acometem os animais afetados. O trabalho aborda as causas que podem originar a insuficiência renal aguda, os sinais clínicos e os exames complementares que auxiliam no diagnóstico da doença. O relato conta o caso de um Pinscher de dois anos que veio ao hospital por apresentar um quadro de letargia e vômitos frequentes.
\end{abstract}

Palavras chave: azotemia, doença renal, IRA, fósforo.

\section{Hyperphosphatemia in acute renal failure: Case report}

\begin{abstract}
This case report shows the concern with the high hyperphosphatemia rates in acute kidney failure in dogs, leaving aside the other signals that affect the affected animals. The work addresses the causes that can lead to acute renal failure, clinical signs and complementary tests that aid in the diagnosis of disease. The story tells of 2 years old Pinscher that came to the hospital by presenting a picture of lethargy and frequent vomiting.
\end{abstract}

Keywords: azotemia, kidney disease, IRA, phosphorus

\section{Introdução}

A insuficiência Renal Aguda (IRA) apresentase quando $75 \%$ dos néfrons de ambos os rins perdem sua funcionalidade (Nelson \& Couto, 2010), e pode levar cerca de horas a dias, devido ao declínio intenso na filtração túbuloglomerular, resultando em azotemia (Smeak, 2003; Grauer \& Lane, 1997). A azotemia pode ser pré-renal, renal ou pós-renal. A pré-renal é proveniente da redução da perfusão renal ou aumento da produção de uréia. Quando ocorre insuficiência renal, leva a causa da azotemia renal. A pós-renal é resultado da diminuição na eliminação de urina do organismo por causa de obstrução uretral ou ruptura vesical (Dunn, 2001; Grauer \& Lane, 1997). O prognóstico é influenciado por alguns fatores como a idade do animal, presença de outra doença no organismo, o grau de azotemia, manejo correto dos sinais urêmicos e resposta ao tratamento (Rocha, 2012). A hiperfosfatemia é um grande indicador de IRA. Quando o seu valor ultrapassa 6,5 mg/dL em cães e gatos adultos, pode se afirmar que uma das causas comum para esse resultado é uma insuficiência renal (Nelson \& Couto, 2010). O tratamento para IRA objetiva reduzir lesões renais potenciais que possam acontecer, promove diurese no caso de oligúria e reverte o quadro de uremia (Smeak, 2003; Grauer \& Lane, 1997).

\section{Relato de caso}

Um canino macho, da raça Pinscher, com dois anos, pesando $5 \mathrm{~kg}$ foi atendido no Hospital Veterinário Universitário da Universidade Federal do Paiuí (HVU-UFPI), no horário do plantão noturno, sendo relatado pelo tutor na anamnese que desde as 12:00h do dia que foi atendido o animal apresentou mudança de atitude, de um estado de alerta, para um estado letárgico, acompanhado de episódios frequentes de vômitos e fasciculações. O Tutor relatou também que desconfiava do animal ter ingerido alguma planta tóxica por volta de sua residência. Comentou que o animal às vezes passava o dia sem acesso a água. No exame clínico foi observado que o animal possuía as mucosas orais 
e oculares normais, frequência respiratória elevada e tempo de preenchimento capilar menor que 2 segundos (TPC $<2$ seg).

Foram solicitados os seguintes exames complementares: Hemograma, Bioquímicos Séricos (Uréia, creatitina, TGP, fosfatase alcalina, proteína total, albumina, gloulina, cálcio e fósforo), Sumário de urina e Ultrassom abdominal.

O animal foi internado para início do tratamento, que consistia na administração de diurético (furosemida), protetor de mucosa gástrica (ranitidina), protetor hepático (Ornitil®), antiemetico (maropitant), antibiótico (ampicilina), complexo de vitamina B, suplemento vitamínico e mineral (Glicopan ${ }^{\circledR}$ ), analgésico e antipirético (dipirona), hidróxido de alumínio e fluído constante de ringer com lactato. Após 17 dias de internado o animal teve alta.

\section{Resultados e Discussão}

No exame físico, os resultados encontrados no paciente com IRA foram bem inespecíficos, como letargia e vômitos frequentes. Juntamente com os resultados dos exames complementares, houve uma elucidada sobre o diagnóstico do animal, concordando dessa forma com Forrester (2003), que afirma que os achados da anamnese, exame físico e exames laboratoriais ajudam a diferenciar entre uma IRA e uma Doença Renal Crônica (DRC), além de um diagnóstico diferencial também de outras doenças.

No hemograma (Tabela 1) as alterações foram relevantes para o inicio urgente de um tratamento. $\mathrm{O}$ animal apresentava leucocitose, que se caracteriza um achado comum em IRA, mas apresentou também anemia normocitica normocrômica na primeira coleta, que segundo Forrester (2003) é mais comum em DRC. Na última coleta, o hemograma (Tabela 1) apresentou leucopenia, mas que pode ter origem por estresse, segundo Nero et al. (1977).

Tabela 1. Resultados dos exames de hemograma durante o período de internação.

\begin{tabular}{lcccc}
\hline Hemograma & $30 / 06 / 2014$ & $07 / 07 / 2014$ & $14 / 07 / 2014$ & Valores de Referência \\
\hline Série Branca & & & & \\
\hline Leucócitos totais & 22.000 & 29.300 & 12.300 & $6.000-17.000$ \\
Basófilos & 00 & 00 & 00 & Raros \\
Eosinófilos & 00 & 00 & 00 & $100-1.250$ \\
Mielócitos & 00 & 00 & 00 & 00 \\
Metamielócitos & 00 & 00 & 00 & 00 \\
Bastão & 00 & 00 & 00 & $0-300$ \\
Segmentados & 20.460 & 26.370 & 11.685 & $3.000-11.500$ \\
Linfócitos & 1.546 & 2.930 & 123 & $1.000-4.800$ \\
Monócitos & 00 & 00 & 492 & $150-1.350$ \\
\hline Série Vermelha & & & & \\
\hline Hemácias & 3,66 & 2,18 & 6,83 & $5,5-8,5$ \\
Hematócrito & 22,8 & 13,4 & 44,1 & $12-18$ \\
Hemoglobina & 7,8 & 4,5 & 14,8 & $60-77$ \\
VGM & 62,4 & 61,6 & 64,7 & $32-36$ \\
CHGM & 34,2 & 33,5 & 33,5 & $14-17$ \\
RDW & 13,7 & 14,0 & 14,4 & $200-500$ \\
Plaquetas & 274 & 78 & 228 & \\
\hline
\end{tabular}

No perfil bioquímico (Tabela 2), tanto a uréia como a creatinina estavam aumentados, formando um quadro de azotemia, o que comum em situações de IRA. Somando a azotemia com os sinais apresentados pelo animal, leva a acreditar que havia um quadro de uremia, concordando com Lorenz et al. (1996).

$\mathrm{O}$ valor de fósforo estava bastante elevado no início do tratamento e o de cálcio bem reduzido, o que chama atenção pelo fato da hiperfosfatemia 
ser observada em uma insuficiência renal avançada, causada por falha na excreção desse mineral, assim como afirma Kaneko (1997). O que explica o aparecimento de sinais mais comuns de DRC no hemograma, justamente pela alta concentração de fósforo (Tabela 2).

Tabela 2. Resultados dos exames de perfil bioquímico durante o período de internação.

\begin{tabular}{lccccc}
\hline Bioquímicos & $29 / 06 / 14$ & $02 / 07 / 14$ & $07 / 07 / 14$ & $12 / 07 / 14$ & Valores de Referência \\
\hline Uréia (mg/dL) & 240,0 & 240,0 & 146,3 & 69,2 & $21,4-59,92$ \\
Creatinina (mg/dL) & 5,9 & 4,9 & 1,9 & 1,3 & $0,5-1,5$ \\
TGP (UI) & 72,3 & - & 14,9 & 24,1 & $21-73$ \\
Fosfatase alcalina (U/L) & 39,1 & - & 123,6 & 253,6 & $20-156$ \\
Proteína total (g/dL) & 4,4 & - & 4,7 & 6,4 & $5,4-7,1$ \\
Albumina (g/dL) & 1,2 & - & 1,1 & 1,3 & $2,6-3,3$ \\
Globulina (g/dL) & 3,2 & - & 3,6 & 5,1 & $2,7-4,4$ \\
Cálcio (mg/dL) & 4,1 & 7,6 & 5,0 & 8,8 & $9,0-11,3$ \\
Fósforo (mg/dL) & 33,6 & 14,9 & 8,0 & 3,7 & $2,6-6,2$ \\
\hline
\end{tabular}

O animal apresentou hipoalbuminemia, o que pode ser explicado no caso desse quadro de doença renal pelo fato do rim estar perdendo proteína e pelo catabolismo protéico elevado (déficit energético), de acordo também com González \& Silva (2003).

$\mathrm{O}$ resultado do exame ultrassonográfico não foi específico, apenas afirmando que houve um aumento de radiopacidade na região córtico medular do rim esquerdo, concordando com Grauer (2005).

Com relação a urinálise (Tabela 3) a densidade ficou isostenúrica e houve presença de albumina (proteinúria), o que caracteriza danos tubulares renais. No exame de sedimento achou cilindros hialinos, assim colaborando para o diagnóstico de IRA, segundo Forrester (2003).

Tabela 3. Resultados dos sumários de urina durante o período de internação.

\begin{tabular}{lcc}
\hline Sumário de Urina & $02 / 07 / 2014$ & $12 / 07 / 2014$ \\
\hline Exame Físico & & \\
\hline Volume & $10 \mathrm{~mL}$ & $3,5 \mathrm{~mL}$ \\
Cor & Amarelo pálido & Amarelo-claro \\
Aspecto & Límpido & Levemente turvo \\
Odor & Sui generis & Sui generis \\
Densidade & 1.010 & 1.008 \\
Reação (pH) & 6,5 & 6,5 \\
\hline Exame Químico & & Positivo (30 mg/dL) \\
\hline Albumina & Positivo (100 mg/dL) & Negativo \\
Glicose & Positivo (50 mg/dL) & Negativo \\
Acetona & Negativo & Negativo \\
Sais biliares & Negativo & Negativo \\
Pigmentos biliares & Negativo & Negativo \\
Urobilinogênio & Negativo & Positivo (++) \\
Sangue oculto & Positivo (+) & Negativo \\
Nitrito & Negativo & Exame de Sedimentos \\
\hline Exame do Sedimento & Transicionais e pélvicas, vesicais & Volume insuficiente para realizaça do \\
\hline Células de descamação & Epresença discreta) & \\
Cilindros & & \\
\hline
\end{tabular}




\section{Conclusão}

A persistência da azotemia e principalmente o desequilíbrio do fator cálcio $\mathrm{x}$ fósforo é determinante para o diagnóstico de IRA. O valor alto de fósforo é um sinal alarmante para o início urgente do tratamento, para evitar que o animal entre num quadro de doença renal crônica-DRC, já que a hiperfosfatemia é um sinal de doença renal avançada.

\section{Referências Bibliográficas}

Dunn, J. K. (2001). Tratado de Medicina de Pequenos Animais. 1 ed. São Paulo: Roca, p. 614-618.

Forrester, S. D. (2003). Nefropatias e Ureteropatias. In: Bircahard, S. J.; Sherding, R. G. Manual Saunder - Clínica de Pequenos Animais. SãoPaulo: Roca.

González, F. H. D. \& Silva, S. C. (2003). Introdução à Bioquímica Clínica Veterinária. Porto Alegre: Editora UFRGS.

Grauer, G. F. (2005). Early detection of renal damage and disease in dogs and cats. Veterinary Clinics of North America: Small Animal Practice, 35, 581-596.

Grauer, G. F. \& Lane, I. F. (1997). Insuficiência renal aguda. In: Ettinger, S. J. \& Feldman, E. C. Tratado de Medicina Interna Veterinária. 4 ed. São Paulo: Manole. v. 2, p. 2374-2393.

Kaneko, J. J. In: Harvey, J. W. \& Bruss, M. L. (1997). Clinical Biochemistry of Domestic Animals. 5 ed. New York: Academic Press.
Lorenz, M. D.; Cornelius, L. M. \& Ferguson, D. C. (1996). Terapêutica Clínica em Pequenos Animais. 1 ed. São Paulo: Interlivros.

Nelson, R. W. \& Couto, C. G. (2010). Insuficiência Renal Aguda e Doença Renal Crônica. Medicina Interna de Pequenos Animais. 4 ed. Rio de Janeiro: Guanabara Koogan.p. 647-662.

Nero, J. M. F., Viana, E. S. \& Magalhães, L. M. (1977). Patologia Clínica Veterinária.1. ed. São Paulo: Rabelo e Brasil Ltda.

Rocha, A. M. G. (2012). Insuficiência Renal Aguda: Uma revisão de literatura. Trabalho de Conclusão de Pós-Graduação Lato Sensu, Especialização em Clínica Médica e Cirúrgica de Pequenos Animais. Dourados: UNIGRAN.

Smeak, D. (2003). Distúrbio do Sistema Urogenital. In: Birchard, S. J. \& Sherding, R. G. Manual Saunder - Clínica de Pequenos Animais. São Paulo: Roca. cap. 8, p.10011008 .

Recebido em Março 10, 2016

Aceito em Abril 13, 2016

License information: This is an open-access article distributed under the terms of the Creative Commons Attribution License, which permits unrestricted use, distribution, and reproduction in any medium, provided the original work is properly cited 